\title{
Children, Sex and Media Violence in Nigeria
}

\author{
Rishante, P. S. \\ Department of Television Production \\ NTA Television College, Jos \\ Plateau State, Nigeria \\ E-mail: phorish@yahoo.com \\ Tel: +2348029168325 \\ $\&$ \\ Yakubu, I. M. \\ Department of Television Production \\ NTA Television College, Jos \\ E-mail: ismailayakubu9@yahoo.com \\ Tel: +2347034858001
}

\begin{abstract}
The portrayal of violence and sex in the media has been known to have gain popularity in recent time. There is an evident connection between what is portrayed in the media with what is observed and practiced by children. The paper empirically examined the influence of media sex and violence on children. Ninety junior secondary school pupils were randomly selected for the study; there were 42 males and 48 females that participated in the study. The age range of participants was between 8-16 years. The experimental design was adopted for the study. Two
\end{abstract}

Copyright (C) IAARR, 2014: www.afrrevjo.net Indexed AJOL: www.ajol.info 
hypotheses were tested in the study, and results revealed that media violence significantly influenced child behaviour ( $p=0.0005)$, and there was a significant influence of media sex on child behaviour $(p=0.0005)$. The study suggests that exposure to violent and sexually explicit material is likely to have a negative influence on children's behaviour.

\section{Introduction}

For years there have been arguments on the power the media wield in determining the on goings in the society and in changing human behaviours. This argument extends to its influence on children. The current young generation are exposed to a myriad of media contents which could explain the sex disposition of children and their tendency to subscribe to violent acts. For example, children begin to notice and react to television very early. By the age of three, children will willingly watch a show designed for them $95 \%$ of the time and will imitate someone on television as readily as they will imitate a live person (Singer \& Singer, 1986). The average time children spend watching television rises from about $21 / 2$ hours per day. A study revealed that nearly $70 \%$ of young people reported at least some exposure to sexual and violent films on video (Strouse, Pettey, \&Shatzer, 2011). Given the popularity of these films, it becomes important to examine the impact that viewing such explicit content may be having on children.

The prevalence of the media in developed countries like the United States of America makes children in those regions more prone to this media effect. However, other countries are not void of similar influences since media presence is existent in developing and underdeveloped countries. Nigeria of today also has a pluralistic media with both private and public radio and television stations, newspapers and magazines. Current technology reaches Nigeria with satellite television and social media via the internet. Children in the country have access to these media and the influences are evident in all ways inclusive of their manner of speaking, dressing, and actions.

The Nigerian media claims to be the freest in Africa, mostly fashioning themselves in the like of that of the western world. However, despite boasting of being the freest, there is still serious censorship going on. That is not to say there are no display of sex and violence. Most sex and violence related contents are however viewed mostly on cable satellites, or home videos or the internet.

The interaction of children with the media is more prevalent among today's children than in the past and erodes the communication or relationship they should have with their parents, siblings and friends. Seiter (2005) argued that though the internet provides information, it also serves as a prey on children leading to their 
exploitation. According to Strausburger (1995), violence and sexuality on television and the Internet play significant roles in children's growing up process, and the effects bear on the society in which they live. Buckingham (1993) postulated that "the spectre of children narcotized by television, corrupted by video violence, and the overt sexuality of popular music, their intellect and imagination destroyed by the mindless products of the culture industry...media are seen to be...a primary cause of the breakdown of the family, of social unrest, and of moral decline."

\section{Media Violence}

The results of studies on the effects of televised violence are consistent. According to Huesmann and Eron, (1986), by watching aggression, children learn how to be aggressive in new ways and they also draw conclusions about whether being aggressive to others will bring them rewards. Those children who see TV characters getting what they want by hitting are more likely to strike out themselves in imitation. A large-scale study funded by the Centres for Disease Control and Prevention established a conclusive link between exposure to media violence and adolescents' violent behaviour and general aggression (Boxer, Huesmann, Bushman, O'Brien \& Moceri, 2009). Boys who view violent television programming at ages two to five years are at increased risk for antisocial behaviour at ages seven to 10 years (Christakis \&Zimmerman, 2007). There is consistent evidence that violent imagery on television and in other media increases the likelihood of aggressive or fearful behaviour in younger children, especially in boys (Browne \& HamiltonGiachritsis, 2005).

\section{Media Sex}

Although a number of factors contribute to adolescents' sexual behaviour, the media have been accused of playing a central role in shaping their behaviours (Kaiser Family Foundation, 1996). In a recent survey, 53\% of teens said that they use TV and movies as a source of information about sex and birth control (Kaiser Family Foundation, 1996). This source of sexual learning may be problematic, especially because television often depicts sex as glamorized with attractive characters engaging in such mature behaviour without precaution or consequence.

Public concern over children's exposure to violence and sex in the media is not new (Smith, Moyer-Gusé, \& Donnerstein, 2008). According to Smith et. al., (2008), parents, educators, and policymakers expressed worry that depictions of crime, sex, and love in major motion pictures were having detrimental effects on youth. Yet nearly three decades later, the same concern is on the mind of many child advocates in the world over, especially given the increasingly graphic and explicit forms of media violence and sex available to today's youth. 
Significantly fewer studies have been conducted on the impact of sex in comparison to violence. This is probably due to the fact that there are inherent difficulties in conducting experiments with young people when the topic of sex is involved (Greenberg, Stanley, Siemicki, Heeter, Soderman \& Linsangan, 1993). Despite this fact, a handful of studies have been conducted. Cope- Farrar and Kunkel, (2002) in a study of the top 15 programs viewed among 12- to 17 -year-olds, $82 \%$ of the episodes featured sex at an average rate of 11 sexual interactions per hour. This figure is significantly higher than the amount $(68 \%)$ and frequency (4 scenes per hour) of sex across the entire landscape of television programming (Kunkel, CopeFarrar, Biely, Farinola, \& Donnerstein, 2001). Unlike the previous analyses of primetime television (Kunkel et al., 2001), teens' favourite shows were equally likely to portray sexual behaviours and sexual talk (62\% vs. 67\%, respectively) (Cope-Farrar \& Kunkel, 2002). Furthermore, $75 \%$ of the characters involved in sexual behaviour faced no clear consequences for their sexual behaviour. However, when consequences were portrayed in teens' favourite prime-time shows, they were overwhelmingly positive in nature.

In addition to prime time, another factor that may influence the presentation of sex is genres. One type of genre that contains a great deal of sex is soap operas. Many content analyses have focused on soap operas because of their popularity among young girls (Greenberg \&Busselle, 1994; Heintz-Knowles, 1996). To sum across studies, sex is prevalent on soaps and is most likely to occur between unmarried characters. In the Kunkel et al. (2001) content analysis, $80 \%$ of soap operas portrayed some sexual content. A study of 97 hours of soap operas revealed that verbal and/or visual messages about sex occurred more than 6 times per hour (Heintz-Knowles, 1996). This finding is relatively consistent with other soap studies documenting between 6.64 and 3.67 sexual incidents per hour, respectively (Greenberg \&Busselle, 1994; Greenberg, et al., 1993).

\section{Statement of the Problem}

Television continues to be one of the most powerful and important influences on the health and behaviour of children throughout America. More families own a television than a telephone (Br-inik, 2001). Therefore, the amount of viewing and content of the programs is likely to have an impact on the behaviour of children. Media violence on television is uniquely accessible and pervasive. Violence on television is frequent, usually viewed as inconsequential and often rewarded.

The influence of sex in the media on children's behaviour is an emerging field of study. While there are numerous studies that demonstrate the link between media violence and aggressiveness in children, there is a paucity of studies that demonstrate a connection between media with high sexual content and changes in children's 
sexual behaviour and attitudes in Nigeria; given the popularity of violence and sexual contents in Nigerian media, the need to examine the influence of media sex and violence on the Nigerian child.

\section{Objective of the Study}

The general objective of the study is to examine the effect of sex and violence in the media on children. Specifically, the study examined the following:

1. The influence of sexual content on children's behaviour and

2. The impact of violence in the media on

\section{Research Questions}

The following research questions were stated in the study:

1. Does sexual contents in media impacts on children's behaviour?

2. What is the role of violence in the media on children's behaviour?

\section{Research Hypotheses}

The following hypotheses were tested in the study:

H1: Sexual contents in media will have a significant effect on children's behaviour

H2: $\quad$ Violence in the media will have a significant impact on children's' behaviour

\section{Methodology}

\section{Population}

The study population consisted of 90junior secondary school pupils aged 8 to 16years attending public and a private school in the Middle-belt zone of Nigeria. Males were 42and females were.

\section{Sampling and Sample size}

A simple random sampling method was employed in this study in selecting 45 pupils from a public junior secondary school, and 45 pupils from a private junior secondary school. A total of 90 samples were selected for study from twojunior secondary schools chosen for the study.

\section{Instrument for Data collection}

A questionnaire containing the following questionnaires were administered to the respondents. 
Buss-Perry Aggression Questionnaire: The Aggression Questionnaire (Buss \& Perry, 1992) is one of the most used instruments to assess aggression; itincludes 29 items grouped into 4 aspects of human aggression, and gives a summative score indicative of the level of aggression.

Sexual Facts Questionnaire: The Sexual Facts Questionnaire is a 12-item questionnaire developed by the researcher to examine the level of knowledge as regards sexual issues such as sex, sexual body parts, and puberty. Scores on the sexual facts questionnaire ranged from $0-24$, with a higher score indicative of good knowledge about human sexuality.

\section{Method of Data Collection}

Forty-five junior secondary school pupils from junior secondary 1 to 3 were randomly selected from a private school, and another 45 pupils were selected from a public school. The pupils in each school were randomly divided into three groups of 15 , and labelled groups ' $A$ ', 'B' and ' $C$ ' respectively. Group ' $A$ ' were shown a 20 minute video clip of documentary on marine life; group ' $B$ ' were shown a 20 minute video clip with violent content; and group ' $\mathrm{C}$ ' were shown 20 minute video clip on sex education. After 10 minutes of the end of the clips, the pupils were administered questionnaires on aggression and sexuality. Completed questionnaires were then scored and analysed.

\section{Results}

Table 1: Age and Gender Distribution of Respondents

$\begin{array}{lll}\text { Age Group } & & \\ 8-10 & 14 & 15.5 \\ 11-13 & 42 & 46.7 \\ 14-16 & 34 & 37.8 \\ \text { Total } & 90 & 100 \\ \text { Gender } & & \\ \text { Male } & 42 & 46.7 \\ \text { Female } & 48 & 53.3 \\ \text { Total } & 90 & 100\end{array}$


Table 1 revealed the age and gender distribution of the respondents, which indicated that $15.5 \%$ of the respondents were between the age ranges of 8-10 years, the majority $(46.7 \%)$ of the respondents were between $11-13$ years, and $37 \%$ of the respondents were between 14-16 years of age. There were 42 male and 48 female respondents in the study.

Figure 1 shows that the group exposed to documentary clip had a mean score on sexuality of 11.93, those exposed to video clip with high level of violent content had an sexualitymean score of 9.97, while the group exposed to a video clip on sex education had a sexuality mean score of 17.63 . The line graph revealed that the group exposed to visual sex education video clip content had a higher mean score on sexuality.

\section{Figure 1: Mean score on sexuality}

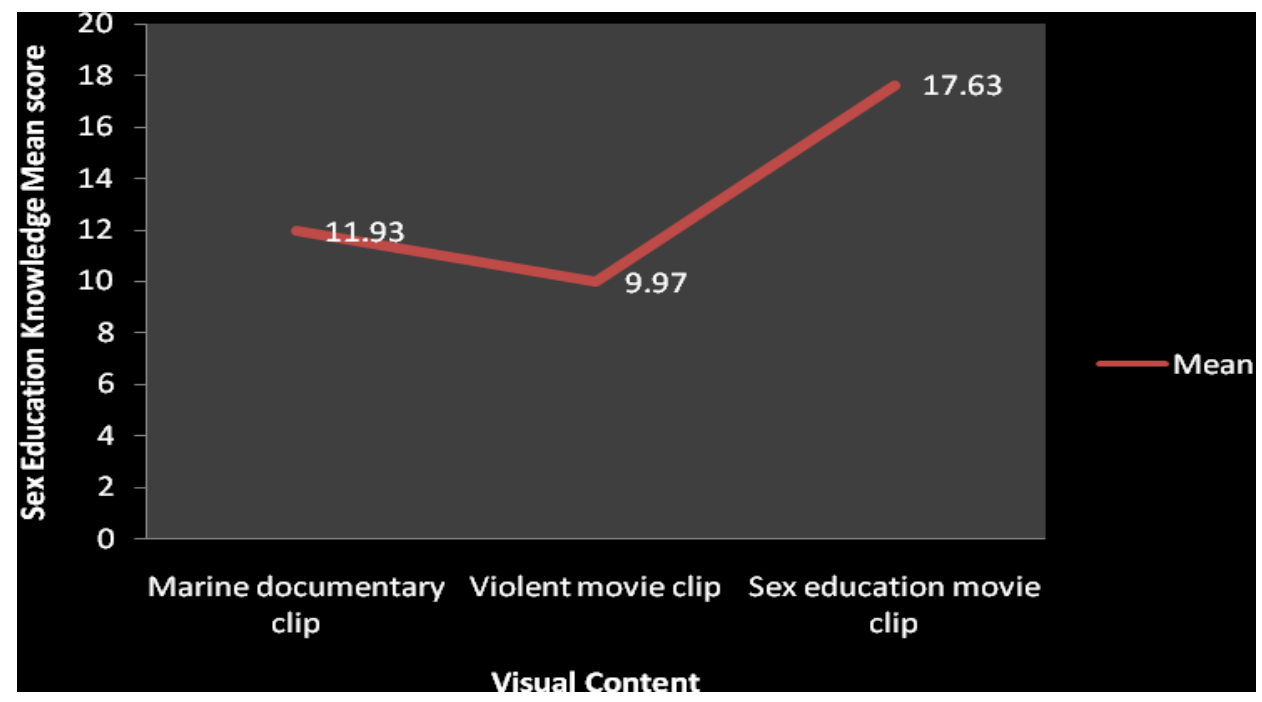

Figure 2 show the mean score on aggression behaviour across the study groups, indicating that the study group that were expose to a video clip on marine life had a mean aggression score of 52.03, those exposed to a video clip with high level of violent content had an aggression mean score of 69.77, while the group exposed to a video clip on sex education had an aggression mean score of 46.4. The line graph revealed that the group exposed to visual aggression content had a higher mean score on aggression behaviour. 
Figure 2: Mean score on Aggression Behaviour

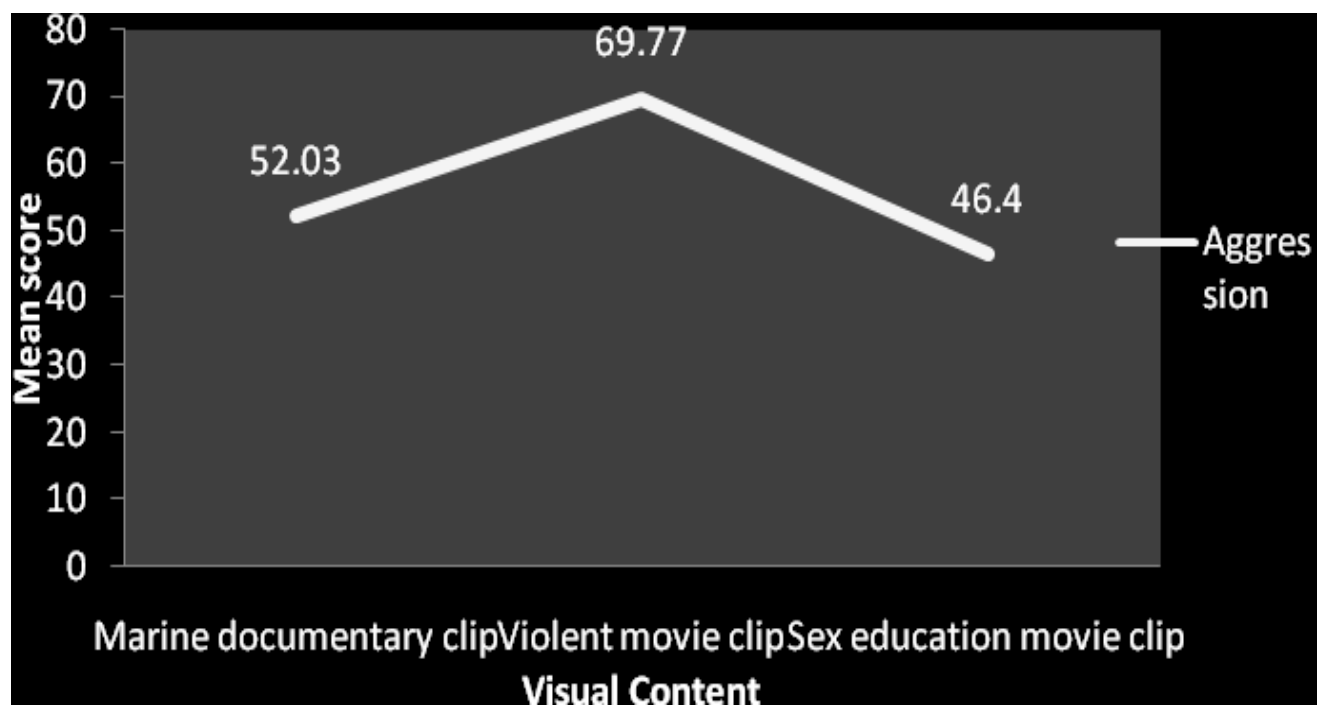

\section{Hypothesis 1:}

The results of table 2 indicated that children exposed to media sex significantly exhibited sexual knowledge than the children not exposed to media sex, $\mathrm{F}(2,87)=51.358, \mathrm{p}=0.0005(\mathrm{p}<.05)$. This means that exposure of children to media sex will lead to the display of sexual behaviour.

\section{Table 2:}

\begin{tabular}{lcccc}
\hline Study Group & Mean & $\begin{array}{c}\text { Standard } \\
\text { Deviation }\end{array}$ & F & p-value \\
Marine documentary & 11.93 & 2.52 & & \\
Violent clip & 9.97 & 2.94 & & 0.0005 \\
$\begin{array}{l}\text { Sex education movie } \\
\text { clip }\end{array}$ & 17.63 & 3.58 & & \\
\hline
\end{tabular}




\section{Hypothesis 2:}

Results of table 3 revealed that children exposed to media violence significantly had higher aggression attitude thanchildren not exposed to media violence, $\mathrm{F}(2,87)=11.946, \mathrm{p}=0.0005(\mathrm{p}<.05)$. This implies that exposure to media violence of children leads to aggressive behaviour.

\section{Table 3: ANOVA for Sexual Behaviour}

\begin{tabular}{lcccc}
\hline Study Group & Mean & $\begin{array}{c}\text { Standard } \\
\text { Deviation }\end{array}$ & F & p-value \\
Marine documentary & 52.03 & 15.55 & & \\
Violent clip & 69.77 & 27.74 & & 0.0005 \\
Sex education movie clip & 46.40 & 10.44 & & \\
\hline
\end{tabular}

\section{Discussion}

Results of the hypotheses testing revealed that exposure to media sex and violence significantly impacted on children's behaviour in terms of their sexual and attitude towards aggression. Research in this area has demonstrated that exposure to, sexually violent media contents which are mostly films can lead to a desensitization effect, such that viewers experience less negative emotional arousal (e.g., anxiety) with heavy viewing (Linz, Donnerstein, \& Penrod, 1988). This effect has been demonstrated using self-report as well as physiological measures of arousal.Research suggests that early exposure to violent and sexually explicit material is likely to have a negative influence on children (Cline, Cooper, Watson, Lefever\& Paul, 2013).

Children process sexually explicit information differently than adults do. In the past, it was thought that children simply did not understand sexually explicit information and therefore were unaffected by exposure. Children are generally concrete thinkers and do not have complex abstract thinking capabilities. Research now shows that although they are incapable of processing the information, they may store it and continue to be reminded of it as they grow older (Cline, et. al., 2013).

The way in which children learn, makes the portrayal of violence, sex, drugs, and alcohol within the media an important contributor to the behavior of children. Social Learning Theory suggests that children learn by watching, imitating and assimilating. Television may teach positive or negative messages to children about 
conflict resolution, gender roles, courtship patterns, and sexual gratification. The large quantity of television viewed by youth and the quality of the programming are instrumental in shaping children's attitudes pertaining to methods of conflict resolution, sexual behaviuor, drugs and alcohol, and stereotypes of men and women (Earles, Alexander, Johnson, Liverpool \& McGhee, 2002). The primary effects of media exposure are increased violent and aggressive behavior, increased high risk behaviors, including alcohol and tobacco use, and accelerated onset of sexual activity (Villani, 2001).

\section{Recommendations}

The following recommendations to regulate the effect of media violence and sex on children are provided:

1. Education of media usage: Parents should play their roles as educators to their children on television viewing. Creating the right available media materials and with proper instruction, or provision of the right cognitive tools for children to help them resist the influence of negative media influence.

2. Use of Blocking Soft-wares: Parents should engage in parental supervision by determining what is accessible for children, through the use of soft-wares developed for blocking adult sites and other unwanted sites on the internet.

3. Better Parent Child relationship: Parents who have a better working relationship with their children tend to gain their confidence and complete respect. Thus such children will confide in their parent $\mathrm{s}$ enough to discuss anything. Also, parents tend to have control over the children, not the coercive type, but the type out of total respect for them.

4. Religion: In Nigeria, religion is very focal and an inseparable part of the society. With proper religious instruction children tend to avoid violence and unwanted sexual relations. Despite the heavy media presence, the instruction such children receive from home, school and places of worship have a bearing on their responses.

5. Co-viewing culture: Families could always ensure that children watch television programmes in the presence of a responsible adult. And of course the adult should make the children feel at home with him or her and be free to ask him. This is more like a mentoring strategy. In the typical African traditional sense parents often play local games together with their children and eat from the same tray. This is typical in Northern Nigeria. If this culture pours into children viewing, then there will be better control for children. 
6. Regulation: The Nigerian film and movie censorship board should be more proactive in tagging of movies with parental guidance.

\section{Conclusion}

In summary, there is a clear cut effect resulting from viewing of televised sexual and violent contents in the media on sexual and aggressive behaviour of children. Influences abound from varying angles, and they are more impactful on children. If in today's time, the main influence is the media, then serious attention should be given to this. The morals of the Nigerian society generally frown at violence and illicit sex. With the pervasiveness of the Nigerian media and the new media which is gradually finding its way to be accessible to every child in the country, more aggressive measures need to be taken to address these.

The changing media and nature of today's family and advancement in technology, all encompass to increase the pervasiveness of the media and consequently the relay of sexual and violence inclined messages to children. Modern living for children of today involves the media of present time that includes the internet and satellite television. These influence the decisions, attitude and behaviours of children. These young ones learn of sex and violence from the media and in the manner the media presents it to them raw without any sense of control or censorship. In conclusion, media sex and violence has many unhealthy effects on children. Even though sex and violence has been and will continue to be a staple of our media environment, it is appropriate to speak out when especially problematic presentations are aired in contexts in which children are likely to see them and when inappropriate programming is actively marketed to vulnerable young people.

\section{References}

Boxer, P., Huesmann, L. R., Bushman, B., O’Brien, M., \& Moceri, D. (2009). The role of violent media preference in cumulative developmental risk for violence and general aggression. Journal of Youth \& Adolescence, 38, 417428.

Buckingham, D. (1993). Reading audiences: Young people and the media. Manchester: Manchester University Press.

Br-inik PJ. (2001). Violence on TV and aggression in children. West Journal of Nursing Research; 23, 5-7.

Christakis, D. A., \& Zimmerman, F. J. (2007). Violent television viewing during preschool is associated with antisocial behaviour during school age. Paediatrics, 120, 993-999 
Cline, V., Cooper, S., Watson, B., Lefever, S., \& Paul, P (2013). Impact of viewing sexually explicit material. Canadian Centre for Child Protection.

Cope-Farrar, K., \& Kunkel, D. (2002). Sexual messages in teens' favourite primetime television programs. In J. Brown, J. Steele, \& K. Walsh-Childers (Eds.), Sexual teens, sexual media, 59-78. Mahwah, NJ: Lawrence Erlbaum.

Earles, K.A., Alexander, R., Johnson, M., Liverpool, J., \& McGhee, M (2002). Media influences on children and Adolescents: violence and sex. Journal of the National Medical Association, 94, (9).

Greenberg, B., \& Busselle, R. (1994). Soap operas and sexual activity. Report Prepared for the Kaiser Family Foundation, Menlo Park, CA.

Greenberg, B., Stanley, C., Siemicki, M., Heeter, C., Soderman, A., \&Linsangan, R. (1993). Sex content on soaps and prime-time television series most viewed by adolescents. In B. S. Greenberg, J. D. Brown, \& N. L. Buerkel-Rothfuss (Eds.), Media, sex, and the adolescent. Cresskill, NJ: Hampton.(pp. 29)

Heintz-Knowles, K. (1996). Sexual activity on daytime soap operas: A content analysis of five weeks of television programming. A report to the Kaiser Family Foundation, Menlo Park, CA.

Huesmann, L. R., Eron, L. D., Klein, A., Brice, P., \& Fischer, P. (1983). Mitigating the imitation of aggressive behaviors by changing children's attitudes about media violence. Journal of Personality and Social Psychology, 44.

Kaiser Family Foundation, (1996). Teens on Sex: What They Say About the Media as an Information Source. Retrieved from: http://kff.org/hivaids/teens-on-sexwhat-they-say-about/. Accessed 10th May 2014.

Kunkel, D., Cope-Farrar, K., Biely, E., Farinola, W., \& Donnerstein, E. (2001). Sex on TV (2): A biennial report to the Kaiser Family Foundation. Menlo Park, CA: Kaiser Family Foundation.

Linz, D. G., Donnerstein, E., \& Penrod, S. (1988). Effects of long-term exposure to violent and sexually degrading depictions of women. Journal of Personality and Social Psychology, 55(5), 758-768.

Seiter, E. (2005).The Internet Playground. New York: Peter Lang Publishing, Inc.

Singer, D., \& Singer, J. (1986). Family experiences and television viewing as predictors of children's imagination, restlessness, and aggression. Journal of Social Issues 42, 107-124. 
Strasburger, V. C. (1995). Adolescents and the media: medical and psychological impact. USA: Sage Publications, Inc.

Strouse, J. S., Pettey, G., \& Shatzer, M. (2011). Adolescents' and young adults' exposure to sexually oriented and sexually explicit media. In B. S. Greenberg, J. D. Brown, \& N. L. Buerkel- Rothfuss (Eds.), Media, sex, and the adolescent, 99-113. Cresskill, NJ: Hampton.

Smith, S. L., Moyer-Gusé, E., \& Donnerstein, E. (2008). Media violence and sex: what are the concerns, issues, and effects? Media Research, 541-566

Villani S (2001). MD. Impact of media on children and adolescents: A 10-year review of the research. Journal of American Academy of Child \& Adolescent Psychiatry; 40, pp. 392-401. 